\title{
DIMENSIONAL AND MORPHOLOGICAL ANALYSIS OF THE DETRITUS FROM SIX EUROPEAN WOOD BORING INSECTS
}

\author{
Bobadilla I. ${ }^{1, \uparrow}$, Arriaga F. ${ }^{1}$, Luengo E. ${ }^{2}$, Martínez, R. ${ }^{1}$
}

\begin{abstract}
Detailed morphological and dimensional analysis of the detritus deposited in the galleries of woodboring insects was performed for some of the most common xylophagous insect larvae in timber construction in Spain. The samples studied belong to six species of four common families of borers: Cerambycidae, Anobiidae, Curculionidae and Lyctidae. The samples were provided by Spanish and German companies and laboratories. The detritus was assessed for size, shape, and colour and, for different species, was found to show morphological and dimensional differences, enabling better and faster identification of these destructive agents. Frass shape and colour assessment together with statistical dimensional data of the six species are presented. A predictive function based on length and width variables of the detritus is proposed, using multivariate discriminant analysis methodology. This function has been proven to be more than $78 \%$ effective in tests of the model.
\end{abstract}

Keywords: Faecal pellets, frass, wood boring insects, identification, construction timber, size measurements.

\section{INTRODUCTION}

Biological damage is often found in city centres where buildings are over 100 years old, in structural wood, joinery and furniture on inspection or when renovation work is carried out. Damage by wood-boring insects is especially frequent if protection was not taken into account during design and if maintenance has been overlooked for years or even decades.

One of the most complex and necessary tasks in building assessment is the identification of the destructive agents in order to assess their importance. This task makes it possible to implement corrective measures and eventually eradicate the insects however usually requires the participation of technical experts.

One of the basic tools for identification is the analysis of the attacked wood. The insects that cause damage are rarely found, but each species has a characteristic form of attack. Almost all of these insects leave woody debris or other materials inside the galleries they make.

The four most common holometabolous insect families in Spain that attack wooden structures and joinery are Cerambycidae, Anobiidae, Curculionidae and Lyctidae, all of which belong to the order Coleoptera (Table 1).

\footnotetext{
${ }^{1}$ Universidad Politécnica de Madrid. UPM. ETSIMFMN, Laboratorio de Industrias de los Productos Forestales. Madrid, Spain.

${ }^{2}$ Asociación de Investigación Técnica de las Industrias de la Madera. AITIM. Madrid, Spain,

^ Corresponding autor: i.bobadilla@upm.es

Received: 09.12.2014 Accepted: 09.08.2015
} 
Cerambycidae are usually easily identified by the larger size and different shape of their galleries and debris. However, misidentification of the other three families is more frequent, due to their similar size and characteristics. In this paper, information offered by the material found inside galleries was used to correctly identify family and species.

Very few references can be found on the identification of wood-boring insects based on the size and shape of frass in their galleries. Morphological studies of the frass mixture in wood-boring insect galleries have been undertaken by other authors to differentiate insect species attacking trees such as in American red oak (Hay 1968), or to identify termite attack on fossil wood (Sutherland 2003, Francis \& Harland 2006). Also, the assessment of frass contained in Baltic amber has been pointed out as a possible tool to identify insects and thus help characterise former forest environments (Nuorteva et al. 2008). Dimensional and morphological analysis of the galleries and exit holes of these species is covered in many references (Oevering \& Pitman 2002). Chemical characterisation of faecal pellets and waste deposited by termites has been used to determine species (Haverty et al. 2004). Finally, the total amount of frass has been used to estimate the intensity of Cossidae family xylophagous attacks (Demolin et al. 2011)

Previous studies suggest that statistical models can be applied to size and shape differences between the detritus of different families of wood-boring insects, to identify them in construction timber (Bobadilla et al. 2008).

The aim of this paper was to perform a detailed dimensional and morphological analysis of detritus, facilitating the identification of some of the most common species of wood boring insects in Spain. Colourimetric assessment was used as a secondary tool, which also offered interesting information in some cases.

\section{MATERIALS AND METHODS}

A total of 4600 measurements (length and width) of 2300 detritus elements (frass or faecal pellets) were obtained from 23 samples of attacked wood. Details of the samples and the wood-borer species in question are summarised in Table 1.

Nine of the 23 wood samples were collected from buildings more than 100 years old located in Spanish city centres, and 14 samples were obtained from different Spanish and German laboratories.

The wood-boring insect species present in the samples were identified based on gallery and hole size, wood species, building inspection information (when available), and visual inspection of the detritus.

The detritus was extracted from galleries in samples for detailed visual analysis and measurement. A Nikon SMZ-2T binocular microscope, a Nikon DS-5M digital image capture device, and a specific biometric program, Nikon DS-L1 were used to examine the detritus. The detritus was only collected from gallery exit holes to ensure that it was only from the final growth stages of the identified species.

One hundred random faecal pellets were selected from each wood sample for assessment (Table 1), according to their origin and the operator that performed the measurements.

Both length and width of each faecal pellet were measured using the equipment described above (Figure 1). Statistical analysis of all measurement data was performed in search of significant differences between species using Anova tests, to assess the mean results and variability corresponding to each species and to finally propose a discriminant model estimation using multivariate analysis. 
Qualitative visual analysis of the faecal pellets was performed and pellets were categorised as in (Figure 1): flat base cylindrical pellets, curved or pointed base cylindrical pellets, cookie form pellet, or detritus without any of the above shapes. Although this was subjective it was a useful means for identifying some wood-boring insects.

Table 1. Number of samples, origin, wood species and measurements of detritus elements or faecal pellets for each species.

\begin{tabular}{|c|c|c|c|c|}
\hline $\begin{array}{l}\text { Insect Species } \\
\text { (Family) }\end{array}$ & $\begin{array}{l}\text { Number } \\
\text { of wood } \\
\text { samples }\end{array}$ & $\begin{array}{c}\text { Sample } \\
\text { Origin }\end{array}$ & Wood Species & $\begin{array}{l}\text { Number } \\
\text { of pellets }\end{array}$ \\
\hline \multirow{2}{*}{$\begin{array}{l}\text { Anobium punctatum De Geer. } \\
\text { (Annobidae) }\end{array}$} & 2 & 2 & Pinus sylvestris & 200 \\
\hline & 2 & 3 & Quercus robur & 200 \\
\hline $\begin{array}{l}\text { (Annobidae) } \\
\text { Calymmaderus solidus Kiesw. } \\
\text { (Annobidae) }\end{array}$ & 2 & 4 & Pinus sylvestris & 200 \\
\hline $\begin{array}{l}\text { Xestobium rufovillosum De } \\
\text { Geer. } \\
\text { (Annobidae) }\end{array}$ & 3 & 5 & Quercus robur & 300 \\
\hline \multirow{2}{*}{$\begin{array}{l}\text { Hylotrupes bajulus L. } \\
\text { (Cerambycidae) }\end{array}$} & 4 & 1 & Pinus sylvestris & 400 \\
\hline & 2 & 6 & Pinus sylvestris & 200 \\
\hline \multirow{2}{*}{$\begin{array}{l}\text { Lyctus brunneus Steph. } \\
\text { (Lyctidae) }\end{array}$} & 4 & 3 & \multirow[t]{2}{*}{ Quercus robur } & 400 \\
\hline & 2 & 6 & & 200 \\
\hline $\begin{array}{l}\text { Pselactus spadix } \mathrm{H} . \\
\text { (Curculionidae) }\end{array}$ & 2 & 6 & Pinus pinaster & 200 \\
\hline \multicolumn{5}{|c|}{$\begin{array}{l}\text { 1. INIA, Instituto Nacional de Investigaciones Agrarias. Spain } \\
\text { 2. BAM (Bundesanstalt für und Prüfung Materialforschung, Federal Institute for Materials } \\
\text { Research and Testing). Germany } \\
\text { 3. MPA Eberswalde (Brandenburg Materialprüfanstalt GmbH, Materials Testing Institute } \\
\text { 4. TE Brandenburg). Germany. } \\
\text { 5. TECNA-RENTOKIL Wood Pest Company Division. Spain. } \\
\text { 6. AITIM. Asociación de Investigación Wood Biotek. Spain. }\end{array}$} \\
\hline
\end{tabular}

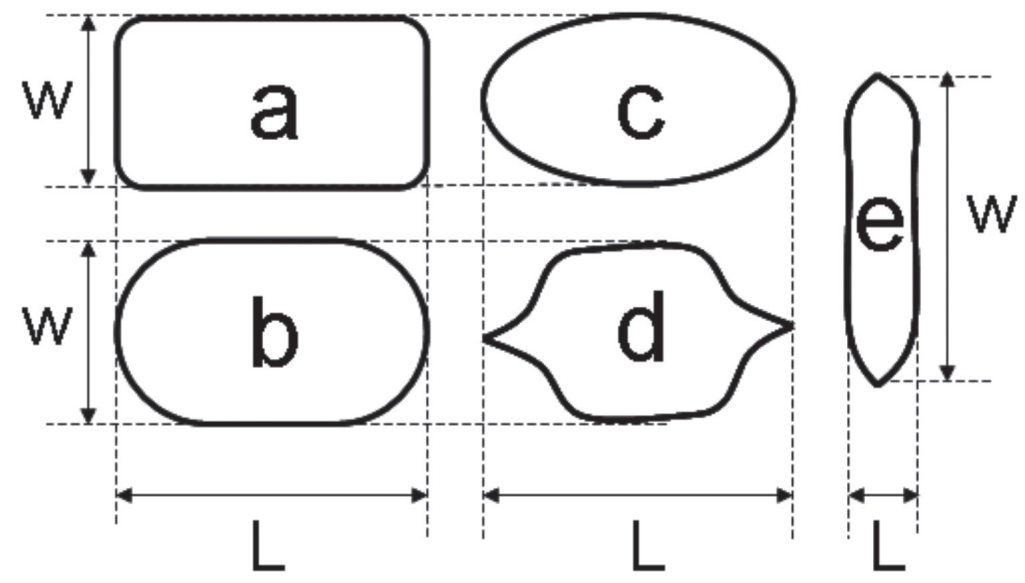

Figure 1. Faecal pellet patterns used to identify the insect ( $W=$ pellet width, $L=$ pellet length): a) flat base cylindrical elements; b, c and d) curved or pointed cylindrical elements;

e) flat or cookie-shaped elements. 
Colour assessment: The colour of the faecal pellets and the similarities and differences between groups or within the same sample were qualitatively checked. To simplify this process, the authors differentiated only between light and dark colours, together with homogeneous or heterogeneous colour within the pellets extracted in each sample. It should be noted that the type of wood and pathological state of the sample can affect colour, so the colour of healthy wood has to be assumed to be the "reference light tone", while darker-than-reference light tone is often related to the accompanying fungal wood decay associated with some of the insects studied. Photographs were taken to highlight the differences between samples (Figure 2).

\section{RESULTS AND DISCUSSION}

\section{Morphological Analysis}

The main morphological characteristics observed for the species studied were:

Anobium punctatum De Geer: homogeneous cylindrical shaped faecal pellets, with rounded or slightly pointed ends. Figure 1, items c and d, and Figure 2.

Calymmaderus solidus Kiesw: homogeneous cylindrical shaped faecal pellets with rounded or slightly pointed ends. Their appearance is more compact than in A. punctatum. Figure 1, items c and d, and Figure 2.

Xestobium rufovillosum De Geer: homogeneous flattened cylindrical cookie-shaped faecal pellets, with slightly convex faces. Figure 1, item e, and Figure 2.

Hylotrupes bajulus L: homogeneous clearly cylindrical faecal pellets with flattened or very slightly rounded ends. Figure 1, item a, and Figure 2.

Pselactus spadix $\mathrm{H}$ : heterogeneous cylindrical faecal pellets with rounded ends. Figure 1, items a and $b$, and Figure 2.

Lyctus brunneus Steph: heterogeneous shapeless frass, somewhat fibrous when viewed under magnification. (Figure 2).

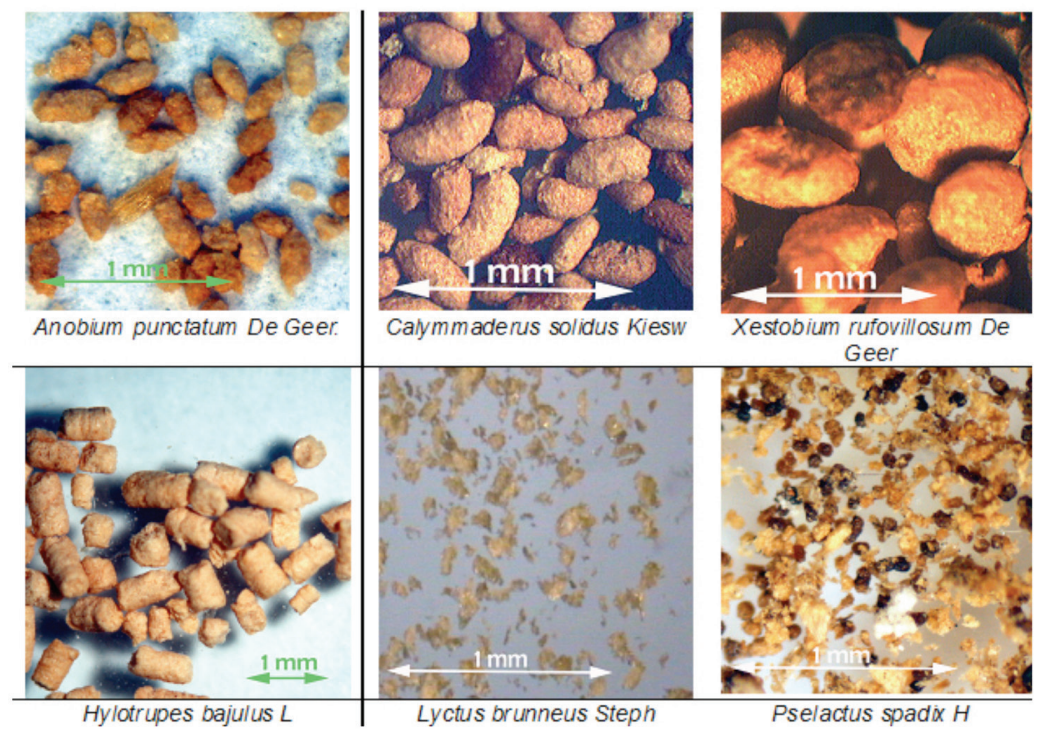

Figure 2. Photographs of the frass analysed for the six species. 
Morphological analysis of the frass from each sample revealed clearly visible differences between the species tested, except for $A$. punctatum and $C$. solidus, which had similarly shaped faecal pellets but differed in small details that required special training to distinguish (Figure 2).

\section{Faecal pellet colour analysis}

The most important colour differences found in the faecal pellets assessed were: Anobiidae (A. punctatum, C. solidus and X. rufovillosum) faecal pellets ranged from light brown to dark brown to almost black within the same sample, depending on the degree of decay of the attacked wood.

Cerambycidae (H. bajulus) faecal pellets and Lyctidae (L. brunneus) frass were generally light in colour that depended primarily on the wood species and the age of the attack, as the colour tends to darken over time.

Curculionidae (P. spadix) frass generally varied in colour from light brown or beige to black within the same sample.

As was the case with the different insect families in work done by Bobadilla et al. 2008, differences in detritus colour were found between some species. This difference is very likely due to the pathological state of timber, as a darker colour is common when the attacked timber shows signs of fungal decay. Cerambycidae (H. bajulus) and Lyctidae (L. brunneus) usually attack sound sapwood with relatively low moisture content (Arriaga et al. 2002) thus lighter colours may be expected. On the other hand, Curculionidae (P. spadix) are commonly associated with decay, because fungi allow them to digest lignin more fully (Oevering et al. 2003). Anobiidae is also associated with decay in some cases, so that darker and more varied tones are expected depending on whether decay is present.

In summary, colour analysis revealed clear differences between some families and species. This is an important secondary feature which confirms identification, i.e. it differentiates Lyctus brunneus, which is not associated with the colour of decayed timber, from Pselactus spadix, which is usually darker in colour due to the decay in attacked wood.

\section{Statistical dimensional Analysis}

Dimensional measurements of each group of samples (each species) were taken from subgroups of 100 items (faecal pellets). Table 2 displays the results of sample length and width measurements. 
Table 2. Statistical summary of length and width measurements of faecal pellets.

\begin{tabular}{|c|c|c|c|c|c|c|c|}
\hline Species & $\begin{array}{c}\text { Measure- } \\
\text { ment } \\
\text { Group (N. } \\
\text { of elements) }\end{array}$ & $\begin{array}{c}\text { Group } \\
\text { Mean } \\
\text { length } \\
(\square \mathbf{m}) \\
\end{array}$ & $\begin{array}{c}\text { Species } \\
\text { Mean } \\
\text { length } \\
(\square \mathrm{m}) \\
\end{array}$ & $\begin{array}{c}\mathrm{CoV} \\
\%\end{array}$ & $\begin{array}{l}\text { Group } \\
\text { Mean } \\
\text { width } \\
(\square \mathrm{m}) \\
\end{array}$ & $\begin{array}{c}\text { Species } \\
\text { Mean } \\
\text { width } \\
(\square \mathrm{m}) \\
\end{array}$ & $\begin{array}{c}\text { CoV } \\
\%\end{array}$ \\
\hline $\begin{array}{l}\text { Anobium punctatum } \\
\text { De Geer.(Softwood) }\end{array}$ & $\begin{array}{l}\text { AN1 } \\
(200)\end{array}$ & $\begin{array}{c}306,7 \\
(*)\end{array}$ & \multirow{2}{*}{$\begin{array}{c}334,6 \pm \\
6,8\end{array}$} & \multirow[t]{2}{*}{21} & $\begin{array}{c}149,5 \\
(*)\end{array}$ & \multirow{2}{*}{$\begin{array}{c}163,8 \pm \\
2,8\end{array}$} & \multirow[t]{2}{*}{18} \\
\hline $\begin{array}{l}\text { Anobium punctatum } \\
\text { De Geer.(Hardwood) }\end{array}$ & $\begin{array}{l}\text { AN2 } \\
(200)\end{array}$ & $\begin{array}{c}362,5 \\
(*)\end{array}$ & & & $\begin{array}{c}178,1 \\
(*)\end{array}$ & & \\
\hline $\begin{array}{l}\text { Calymmaderus } \\
\text { solidus Kiesw. }\end{array}$ & $\begin{array}{l}\text { CA1 } \\
(200)\end{array}$ & - & $\begin{array}{c}458,7 \pm \\
13,9\end{array}$ & 16 & - & $\begin{array}{c}228,4 \pm \\
6,8\end{array}$ & 15 \\
\hline $\begin{array}{c}\text { Xestobium } \\
\text { rufovillosum De } \\
\text { Geer, }\end{array}$ & $\begin{array}{l}\mathrm{XE} 1 \\
(300)\end{array}$ & - & $\begin{array}{c}260,1 \pm \\
11,1\end{array}$ & 16 & - & $\begin{array}{c}671,6 \pm \\
5,4\end{array}$ & 13 \\
\hline \multirow{2}{*}{ Hylotrupes bajulus L. } & $\begin{array}{l}\text { HY1 } \\
(400)\end{array}$ & $\begin{array}{c}975,84 \\
(* *)\end{array}$ & \multirow[t]{2}{*}{$\begin{array}{c}1064,9 \pm \\
16,0\end{array}$} & \multirow[t]{2}{*}{19} & $\begin{array}{c}556,91 \\
(* *)\end{array}$ & \multirow[t]{2}{*}{$\begin{array}{c}580,1 \pm \\
5,7\end{array}$} & \multirow[t]{2}{*}{12} \\
\hline & $\begin{array}{l}\text { HY2 } \\
(200)\end{array}$ & $\begin{array}{l}1238,2 \\
1(* *)\end{array}$ & & & $\begin{array}{l}622,9 \\
(* *)\end{array}$ & & \\
\hline \multirow{2}{*}{$\begin{array}{l}\text { Lyctus brunneus } \\
\text { Steph. }\end{array}$} & $\begin{array}{l}\text { LY1 } \\
(400)\end{array}$ & $\begin{array}{l}99,36 \\
(* * *)\end{array}$ & \multirow{2}{*}{$\begin{array}{c}115,1 \pm \\
8,1\end{array}$} & \multirow[t]{2}{*}{32} & $\begin{array}{l}49,03 \\
(* * *)\end{array}$ & \multirow{2}{*}{$\begin{array}{c}58,4 \pm \\
3,9\end{array}$} & \multirow[t]{2}{*}{34} \\
\hline & $\begin{array}{l}\text { LY2 } \\
(200)\end{array}$ & $\begin{array}{c}146,47 \\
(* * *)\end{array}$ & & & $\begin{array}{l}77,17 \\
(* * *)\end{array}$ & & \\
\hline Pselactus spadix H. & $\begin{array}{c}\text { PS1 } \\
(200)\end{array}$ & - & $\begin{array}{c}113,8 \pm \\
13,9\end{array}$ & 20 & - & $\begin{array}{c}55,9 \pm \\
6,8\end{array}$ & 19 \\
\hline
\end{tabular}

Measurement groups presenting statistically significant differences between them are marked with symbols (*,** and ***).

The dimensional measurements of different samples vary widely in general, with an average Coefficient of Variation (CoV) from 16\% to 21\%, peaking at $32 \%$ in Lyctus, which, in this last case, may be due to the greater variation in shape of its debris.

The ANOVA test of the 100 measurement groups, and the notched box and whiskers plot inspection, show that considering both the mean length and width, the species are in general statistically independent, (Figure 5), except for P. spadix and L. brunneus which are very similar and show no statistically significant differences.

A. punctatum 1

A. punctatum 2

A. punctatum 3

A. punctatum 4

C. solidus 1

C. solidus 2

X. rufovillosum 1

X. rufovillosum 2

X. rufovillosum 3

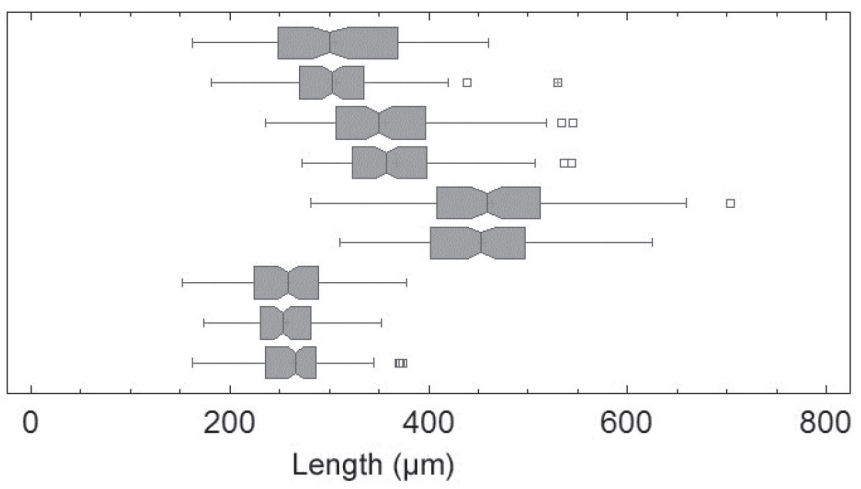

Figure 3. Notched Box and Whisker diagram for length of detritus of the three Anobiidae species subgroups. 
All the samples measured from each species of insect were tested for data normality. Examples are shown in figure 4 for the length histograms of the Anobiidae species family.
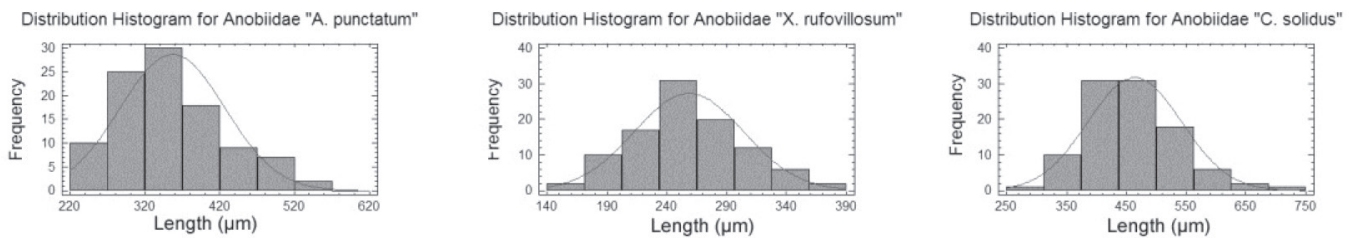

Figure 4. Distribution histograms for length in the Anobiidae family, 100 measurement groups.

The aforementioned factorial ANOVA test also revealed a higher significance for the width of detritus, with which groups can be better differentiated.

A graph summarising mean behavior and differences between species is shown in figure 5 .
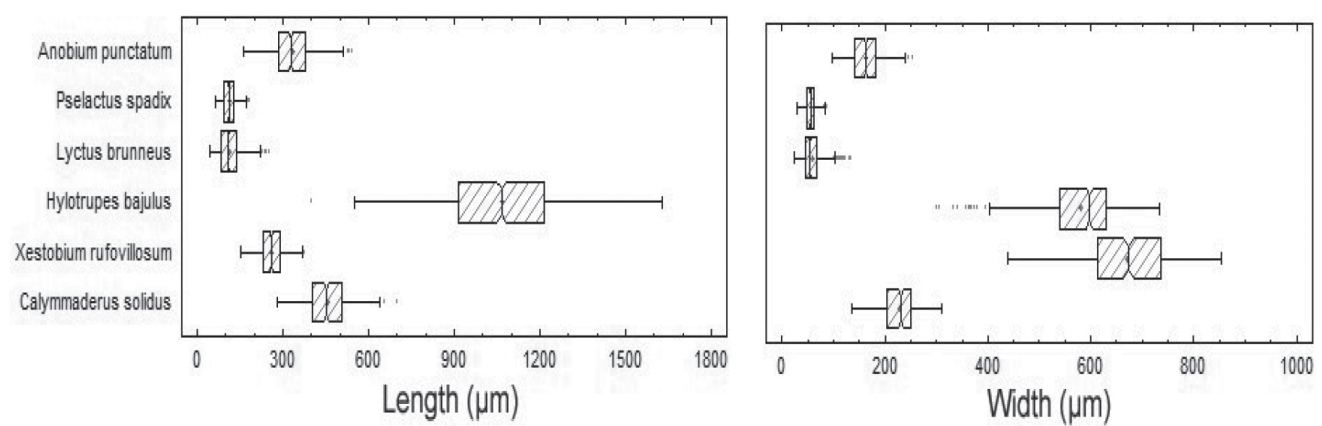

Figure 5. Notched Box and Whisker diagram for mean length and width of detritus of the six species.

In some cases, subgroups of the same species presented statistically significant differences. This may have been due to the difficulty of measuring irregularly shaped debris, as was the case with Lyctus. In other cases however, such as Cerambycidae and Anobiidae, the type of wood attacked (hardwood or softwood) and its density or nutrient content appear to have had a possible influence on the results, however, this will require future research.

The differences between groups of measurements within the same species can be seen in table 2 (marked with asterisks) and an example within the family Anobiidae can be seen in figure 3 . In this figure one can see how three species, $A$. punctatum, $C$. solidus and $X$. rufuvillosum are statistically different, as the boxes do not overlap. It may also be observed that subgroups within the species $C$. solidus and $X$. rufovillosum present no differences, whereas the $A$. punctatum softwood sample subgroups $(1,2)$ are statistically different from the hardwood sample subgroups $(3,4)$. 
In the case of the species A. punctatum, the hardwood sample, which was denser and consequently more difficult to attack, bore larger detritus (Figure 3), so one might conclude that slower development leads to larger larvae. The same conclusion could be drawn from the results obtained with the species $H$. Bajulus from laboratory samples, where wood is enriched with nutrients and larval development is faster, resulting in smaller sizes (Table 2).

\section{Multivariate discriminant functions for dimensional assessment}

Prediction functions were determined by multivariate discriminant analysis, based on the length and width of frass elements. These functions are able to establish the species of the sample at the $95 \%$ confidence level.

The predictive functions follow the form of Equation 1, whose $\mathrm{X}$ and $\mathrm{Y}$ factors and constants are shown in Table 3.

$$
\text { Species }=X x L+Y x W+C \quad \text { (Equation } 1)
$$

where:

$L$ : is the length of the detritus $\mu$

$W$ : is the width of the detritus $\mu$

$C$ is a constant

$X$ and $Y$ are the length and width factors

Species: is the numerical result of each equation for each species

Table 3. Discriminant functions, constants and factors for the six species predictive model.

\begin{tabular}{|l|c|c|c|}
\hline Species & X Factor & Y Factor & Constant \\
\hline Anobium punctatum De Geer. & 0,01757160 & 0,0406189 & $-8,05869$ \\
\hline Calymmaderus solidus Kiesw. & 0,02365600 & 0,0575192 & $-13,78670$ \\
\hline Xestobium rufovillosum De Geer. & $-0,04895430$ & 0,2943860 & $-94,28280$ \\
\hline Hylotrupes bajulus L. & 0,04917920 & 0,1576150 & $-73,69740$ \\
\hline Lyctus brunneus Steph. & 0,00580803 & 0,0149602 & $-2,56278$ \\
\hline Pselactus spadix H. & 0,00595458 & 0,0138935 & $-2,51860$ \\
\hline
\end{tabular}

Figure 6 shows the distribution of length and width measurements of each sample analysed. An overlap of results can be observed between certain species, while others are totally independent. 


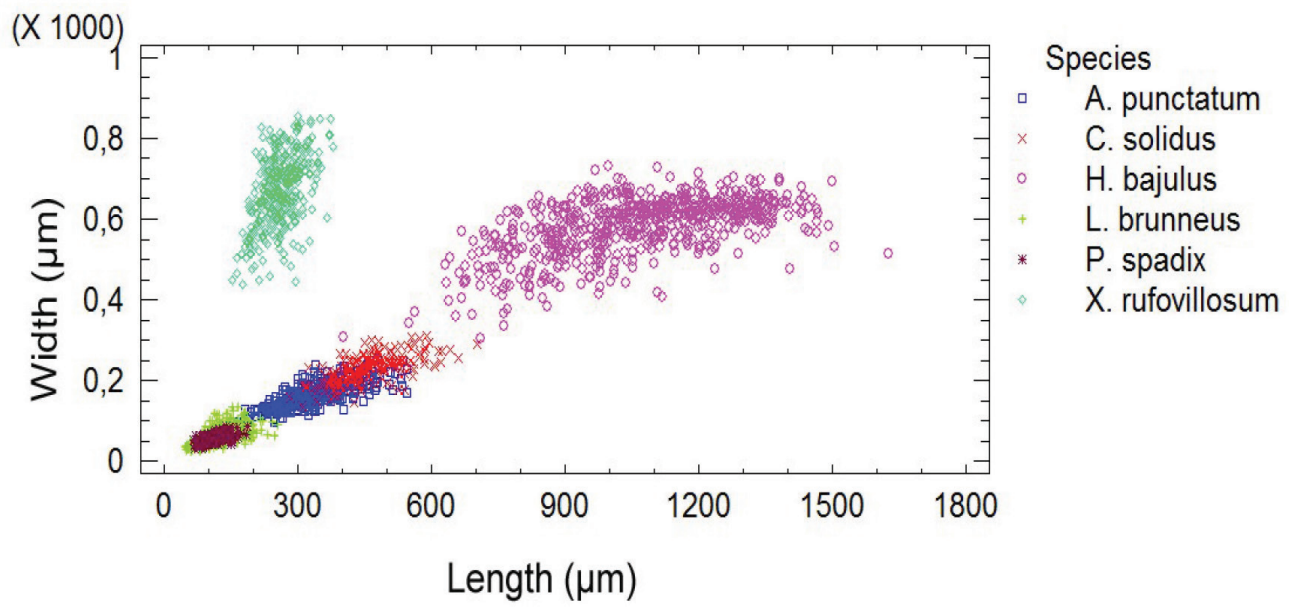

Figure 6. Size distribution diagram by species. A. punctatum (Anobium punctatum De Geer.), $C$. solidus (Calymmaderus solidus Kiesw.), H. bajulus (Hylotrupes bajulus L.), L. brunneus (Lyctus brunneus Steph.), P. spadix (Pselactus spadix H.) and $X$. rufovillosum (Xestobium rufovillosum De Geer).

When the length "L" and width "W" values of a new sample were entered into the equations, the species corresponding to the equation giving the highest value was the most likely to fit the measured sample. The smaller the difference, the greater the proximity between groups and the less clear the classification. Based on the results obtained with the classification equations in the tested samples, the prediction model demonstrated a proven classification effectiveness of $77,1 \%$. The percentages of correct species identification are shown in Figure 7.

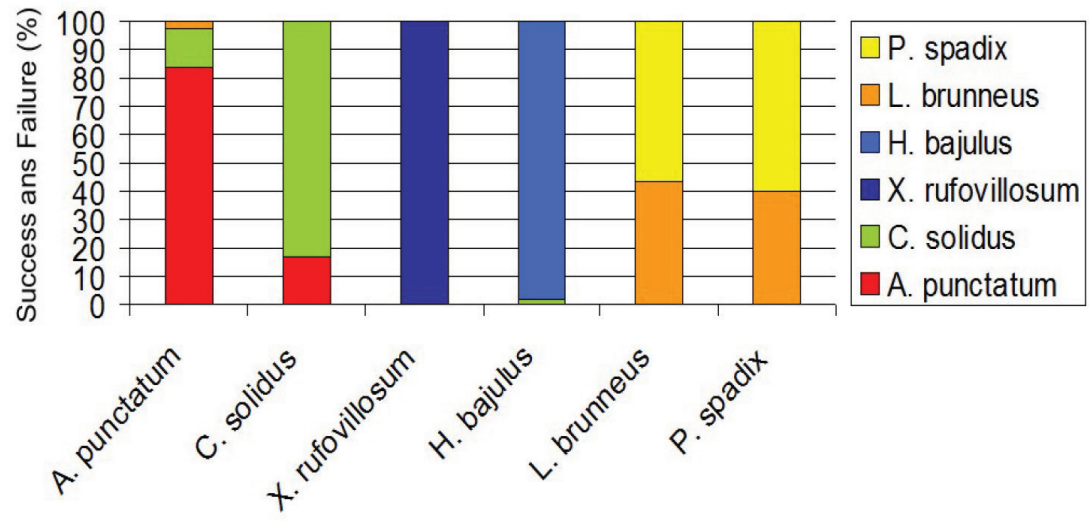

Figure 7. Prediction model success and failure percentage graph.

The $\mathrm{x}$-axis shows target species, and the different colours bars show species identified using prediction model. 
Using 6 new samples and measuring groups of 10 frass elements of each, the prediction model was checked and an overall percentage of success of $78,3 \%$ achieved for the measured values. The percentage of success for each species is shown in Figure 8, where all species were correctly classified except for L. brunneus, with only $40 \%$ accuracy. As expected, L. brunneus was confused with P. spadix. Taking the mean values of the measurements of each sample, all but $L$. brunneus were correctly classified by the proposed prediction model.

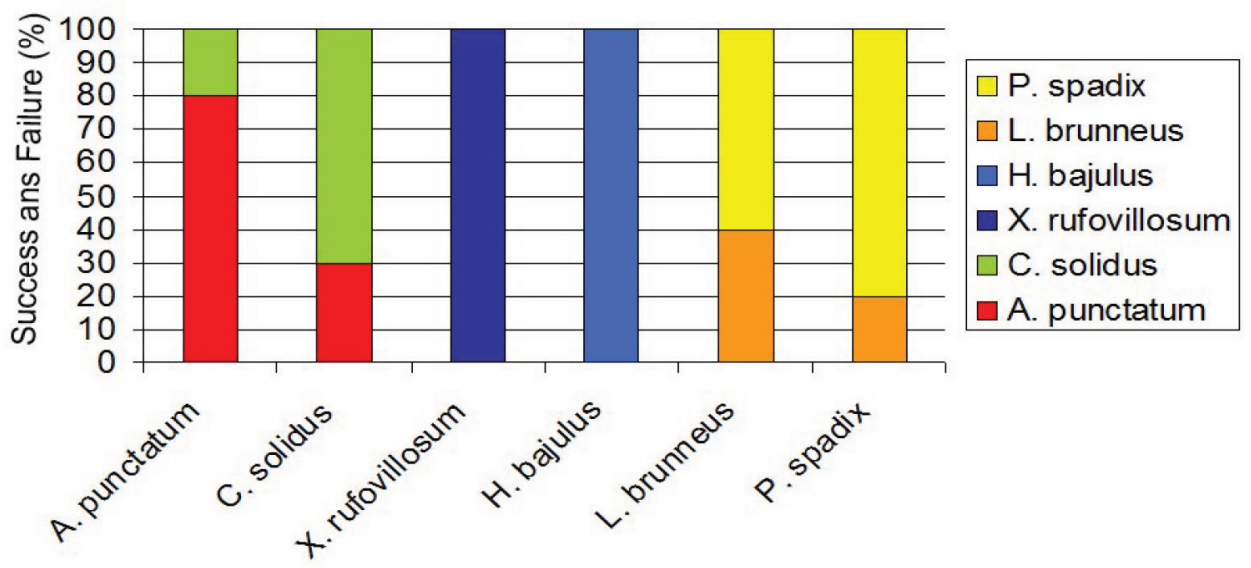

Figure 8. Prediction model success and failure percentage graph, using 6 new samples. The target species can be observed in the $\mathrm{x}$-axis, while the bars in different colours show the species identified using prediction model proposed.

Taking all of the above aspects into consideration, there are enough significant differences between all of the analysed species to make it possible to identify them using detritus size, shape and colour. In fact, without any prior knowledge and by only measuring dimensions, some degree of identification is possible using the presented prediction model. 


\section{CONCLUSIONS}

The analysis of the dimensions of faecal pellets shows that the six species studied can be classified into two groups, A: Hylotrupes bajulus, Xestobium rufovillosum, Anobium punctatum and Calymmaderus solidus, and B: Lyctus brunneus and Pselactus spadix.

A set of multivariate discriminant functions was proposed as a tool for dimensional assessment in the identification of wood borers. The prediction model produced a proven classification effectiveness of $77,1 \%$ ( $78,3 \%$ in the model when using new samples). This procedure was useful to differentiate species within group A but not effective enough when assessing species within group B (L. brunneus and $P$. spadix) with success rates of only $43,2 \%$ and $60,0 \%$, respectively. There were no statistically significant differences in length or width between the detritus of these last two species, being both significantly smaller than those of group A. However, when additionally using morphological and colour data, no doubts arose when separating L. brunneus and P. spadix since the appearance of their frass was very different.

To use the predictive equations, frass must be taken from the galleries closest to the surface, and if possible, from the exit holes themselves, to ensure the faecal pellets obtained correspond to the final larval growth stages. Once collected, a series of at least 10 random measurements should be taken, first checking all of them separately using the predictive model, and then checking their mean values in order to avoid using outlying data. If very similar values are obtained in the equations, data on shape and colour should be added to the dimensional analysis.

The results, obtained with the 6 analysed species, represent an important advance in the application of quantitative and qualitative techniques to the identification of wood-boring insects. This provides a useful tool which improves the accuracy of identification and facilitates the work of the technicians when it is considered with other information such as wood species, geographical location and size and shape of exit holes.

\section{ACKNOWLEDGMENTS}

AITIM, Asociación de Investigación Técnica de las Industrias de la Madera. AITIM-FUCOVASA 2006-2007 and 2010-2011 projects. Spain.

INIA, Instituto Nacional de Investigaciones Agrarias. Maite de Troya and her team. Spain.

CIS Madeira. Centro de Investigación de la Madera de Galicia. David Lorenzo and Manuel Touza. Spain.

BAM (Bundesanstalt für und Prüfung Materialforschung, Federal Institute for Materials Research and Testing). Germany.

MPA Eberswalde (Brandenburg Materialprüfanstalt $\mathrm{GmbH}$, Materials Testing Institute of Brandenburg). Germany.

TECMA-RENTOKIL Wood Pest Company Division. Roberto Martínez. Spain. TECNALIA Centro de Investigación Wood Biotek. Josu Benito. Spain. 


\section{REFERENCES}

Arriaga, F.; Peraza, F.; Esteban, M.; Bobadilla, I.; García, F.; 2002. Intervención en estructuras de madera. Aitim. Madrid. $476 \mathrm{p}$.

Bobadilla, I.; Arriaga, F.; Iñiguez-González, G.; Esteban, M.; Castro, N.; 2008. Identificación de Insectos Xilófagos en madera de construcción mediante el análisis morfológico del detrito. Actas de las II Jornadas de Investigación en Construcción del Instituto Eduardo Torroja. May 22-24. pp:129. Madrid. España.

Demolin, L.; Germano, L.; Alves, S.M.; Nascimento, A.F. 2011. Identification of the wood borer and the factors affecting its attack on Caryocar brasiliense trees in the Brazilian savanna. Acta Scientiarum Agronomy 33(4): 589-596.

Francis, J.E.; Harland, B.M. 2006. Termite borings in early Cretaceous fossil wood. Isle of Wight, UK. Cretaceous Research 27(6): 773-777.

Hay, C.J. 1968. Frass of some wood boring insects in living oak. Annals of the Entomological Society of America 61(2): 225-258.

Haverty, M.; Woodrow, J.; Nelson, L.; Grace, K. 2005. Identification of termite species by the hydrocarbons in their faeces. Journal of Chemical Ecology 31(9): 2119-2151.

Nuorteva, M.; Kinnunen, K.A. 2008. Insect frass in Baltic amber. Bulletin of the Geological Society of Finland 80: 105-124.

Oevering, P.; Pitman, AJ. 2002. Characteristics of attack of coastal timbers by Pselactus sapadix Herbst and an investigation of its life history. Holzforschung 56(4): 335-359.

Oevering, P.; Pitman, A.J.; Pandey, K. 2003. Wood digestion in Pselactus spadix Herbst, a weevil attacking marine timber structures. Biofouling 19(s): 249-254.

Sutherland, J.I. 2003. Miocene petrified wood and associated borings and termite faecal pellets from Hukatere Peninsula, Kaipara Harbour, North Auckland, New Zealand. Journal of the Royal Society of New Zealand 33(1): 395-414. 